\title{
Interaction of a ruthenium hexacationic prism with amino acids and biological ligands: ESI mass spectrometry and NMR characterisation of the reaction products
}

\author{
Lydia E. H. Paul • Bruno Therrien • \\ Julien Furrer
}

Received: 13 April 2012/Accepted: 15 June 2012/Published online: 6 July 2012

(c) SBIC 2012

\begin{abstract}
Reactions between the cationic triangular metallaprism $\left[(p \text {-cymene })_{6} \mathrm{Ru}_{6}(\mathrm{tpt})_{2}(\mathrm{dhnq})_{3}\right]^{6+}\left([\mathbf{1}]^{6+}\right)[\mathrm{tpt}$ is 2,4,6-tri(pyridine-4-yl)-1,3,5-triazine; dhnq is 5,8-dihydroxy-1,4-naphthoquinonato] and Arg, His, Lys, ascorbic acid, lactic acid and glutathione (GSH) have been studied at $37{ }^{\circ} \mathrm{C}$ in aqueous solution at $\mathrm{pD} 7$ using NMR spectroscopy and electrospray ionisation mass spectrometry. Coordination to the imidazole nitrogen atom of His or to the basic $\mathrm{NH} / \mathrm{NH}_{2}$ groups in Arg and Lys slowly displaces the dhnq and tpt ligands from the (p-cymene)Ru units, and subsequently additional coordination to the amino and carboxylato groups forms stable N,N,O metallacycles. Compared with our previously reported study with the analogous metallaprism $\left[(p \text {-cymene })_{6} \mathrm{Ru}_{6}(\mathrm{tpt})_{2}(\mathrm{dhbq})_{3}\right]^{6+}\left([2]^{6+}\right)$ (dhbq is 2,5-dihydroxy-1,4-benzoquinonato), the larger metallaprism $[1]^{6+}$ appears to be significantly more stable, and disassembled in the presence of Arg, His and Lys after only $12 \mathrm{~h}$ of incubation. Moreover, the reaction with His is not complete, since only $14 \%$ of His reacted after more than 1 week of incubation. Solutions of $[\mathbf{1}]^{6+}$ are also able to catalyse oxidation of the thiol group of Cys and GSH to give the corresponding disulfides and of ascorbic acid to give the corresponding dehydroascorbic acid. However, the results are markedly
\end{abstract}

Electronic supplementary material The online version of this article (doi:10.1007/s00775-012-0918-8) contains supplementary material, which is available to authorized users.

L. E. H. Paul · J. Furrer $(\square)$

Department für Chemie und Biochemie,

Universität Bern, 3012 Bern, Switzerland

e-mail: julien.furrer@dcb.unibe.ch

B. Therrien

Institut de Chimie, Université de Neuchâtel,

2000 Neuchâtel, Switzerland different from those obtained with metallaprism $[2]^{6+}$ : the oxidation of Cys and ascorbic acid is not complete, and the formation of intermediate adducts could be evidenced. On the other hand, the oxidation of GSH remains fast and is completed after only $12 \mathrm{~h}$. Oxidation of GSH to give the corresponding disulfide may explain its higher in vitro anticancer activity as compared with $[2]^{6+}$. Our results suggest that metallaprism $[\mathbf{1}]^{6+}$ is more robust than $[2]^{6+}$, may remain intact in the bloodstream and, therefore, may enter cancer cells undamaged, thus confirming the drug delivery potential for such water-soluble organometallic cages.

Keywords Ruthenium - Metalla assemblies - Chelates · Drug delivery · Glutathione oxidation

$\begin{array}{ll}\text { Abbreviations } \\ \text { acac } & \text { Acetylacetonate } \\ \text { dhbq } & \text { 2,5-Dihydroxy-1,4-benzoquinonato } \\ \text { dhnq } & \text { 5,8-Dihydroxy-1,4-naphthoquinonato } \\ \text { DOSY } & \text { Diffusion-ordered spectroscopy } \\ \text { en } & \text { Ethylenediamine } \\ \text { ESI } & \text { Electrospray ionisation } \\ \text { GSH } & \text { Glutathione } \\ \text { GSSG } & \text { Oxidised glutathione } \\ \text { tpt } & \text { 2,4,6-Tri(pyridine-4-yl)-1,3,5-triazine }\end{array}$

\section{Introduction}

The development of new metal anticancer compounds has always been a challenge for inorganic and organometallic chemists. Indeed, since the opportune discovery of the biological activity of cisplatin by Rosenberg et al. [1], almost four decades of intensive research in this field has 
produced only a small number of clinically used compounds, and currently only platinum derivatives for cancer treatments [2-4]. However, with the knowledge acquired during these four decades, medicinal inorganic chemistry and bioorganometallic chemistry are probably advanced enough to make significant steps forward and there are great expectations for the future.

Ruthenium complexes have been known for a long time to possess anticancer properties [5-7], but it was shown only recently that these compounds have several advantages compared with commonly used platinum drugs. Ruthenium complexes are generally more selective towards cancer cells and therefore cause fewer side effects than cisplatin [3]. Phase I clinical trials have already been completed for two inorganic ruthenium-based drugs, namely NAMI-A and KP1019 [4]. Phase II clinical trials have already started for NAMI-A and will soon start for KP1019 [4, 8, 9]. These two compounds possess similar structural features but have very different activity towards cancerous tissue. NAMI-A is most effective against lung metastases, whereas KP1019 is used to treat colon carcinomas.

Since the discovery of the enhanced permeability and retention effect in 1986 [10], the design of supramolecular assemblies of various sizes and functionalities has generated a lot of attention [11-14]. The literature shows many different approaches towards combining transition metal ions with different polydentate ligands to produce large metalla assemblies [15-17]. Our group has designed hexacationic ruthenium metallaprisms able to encapsulate reversibly inside the cavity of planar aromatic molecules or even planar metal complexes such as $\mathrm{Pt}(\mathrm{acac})_{2}$ or $\mathrm{Pd}(\mathrm{acac})_{2}$ (acac is acetylacetonate) [18-20]. The encapsulated metal complexes remain stable, with the physical properties of the prism being retained following encapsulation. Interestingly, the activity $\left(\mathrm{IC}_{50}=23 \mu \mathrm{M}\right)$ of the metallaprism against the A2780 cancer cell line significantly increases with the encapsulation of $\mathrm{Pt}(\mathrm{acac})_{2}$ or $\mathrm{Pd}(\mathrm{acac})_{2}\left(\mathrm{IC}_{50}\right.$ of 12 and $1 \mu \mathrm{M}$, respectively), suggesting transport and leaching of the guest once it is inside the cell [18].

In a recent study [21], we investigated the behaviour of the hexacationic metallaprism $\left[\mathrm{Ru}_{6}(p \text {-cymene })_{6}(\mathrm{dhbq})_{3}\right.$ $\left.(\mathrm{tpt})_{2}\right]^{6+}\left([2]^{6+}\right)$ [dhbq is 2,5-dihydroxy-1,4-benzoquinonato; tpt is 2,4,6-tri(pyridine-4-yl)-1,3,5-triazine] with regard to different biological ligands. We showed that the arene ruthenium metallaprism disassembles upon the addition of Arg, Lys and His and forms stable mononuclear chelate adducts. On the other hand, the metallaprism remained inert towards Met, which is in contrast to what was observed for previously reported ruthenium complexes, which formed stable adducts with Met [22, 23]. Interestingly, the metallaprism was also able to catalyse the oxidation of ascorbic acid, Cys and glutathione (GSH) to form dehydroascorbic acid, cystine and oxidised GSH (GSSG), respectively. This mode of action involving redox processes and oxidation of GSH, which is supposed to be at least partly at the origin of the observed cytotoxicity of some ruthenium complexes [24], has been rarely reported so far [25, 26].

In this study, we report the reactions of a larger hexacationic metallaprism, $\left[\mathrm{Ru}_{6}(p \text {-cymene })_{6}(\mathrm{dhnq})_{3}(\mathrm{tpt})_{2}\right]^{6+}$ $\left([1]^{6+}\right)$ (dhnq is 5,8-dihydroxy-1,4-naphthoquinonato), with a series of biological ligands, and as compared with $[2]^{6+}[21]$, this metallaprism contains a dhnq moiety instead of dhbq. These investigations have been undertaken to clarify the much better cytotoxicity of this prism ( $\mathrm{IC}_{50}$ of $2 \mu \mathrm{M}$ with regard to the $\mathrm{A} 2780$ cancer cell line [27] and $23 \mu \mathrm{M}$ for the prism containing dhbq moieties) and to verify its relative reactivity and stability upon the addition of biological ligands.

\section{Materials and methods}

Chemicals obtained from commercial suppliers were used as received and were of analytical grade. $\mathrm{RuCl}_{3} \cdot n \mathrm{H}_{2} \mathrm{O}$ was obtained from Johnson Matthey, D,L-lactic acid, L-Arg, LCys, L-His and L-Lys were purchased from Acros, GSH was obtained from Sigma-Aldrich and L-ascorbic acid was obtained from Hänseler.

If not stated otherwise, all experiments were performed by mixing solutions of the metallaprism $[1]\left[\mathrm{CF}_{3} \mathrm{SO}_{3}\right]_{6}$ $(2 \mathrm{mg})$ in $1.0 \mathrm{~mL} \mathrm{D}_{2} \mathrm{O}$ with 10 equiv of the different ligands. All reactions were first monitored by $1 \mathrm{D}{ }^{1} \mathrm{H}$ NMR spectroscopy. Two-dimensional homonuclear ${ }^{1} \mathrm{H}-{ }^{1} \mathrm{H}$ and heteronuclear ${ }^{1} \mathrm{H}^{13}{ }^{13} \mathrm{C}$ NMR experiments were performed once the steady state had been confirmed from the ${ }^{1} \mathrm{H}$ NMR spectra. All experiments on $[1]^{6+}$ and biological ligands were undertaken at $\mathrm{pD} 7$, i.e. close to the $\mathrm{pH}$ value of the bloodstream. The $\mathrm{pD}$ values of $\mathrm{D}_{2} \mathrm{O}$ solutions were obtained by use of a glass electrode and addition of 0.4 to the $\mathrm{pH}$ meter reading $[28,29]$. The aim of this work was to study the interactions between $[\mathbf{1}]^{6+}$ and biological ligands in conditions close to physiological conditions; thus, oxygen was not excluded from the solutions.

\section{NMR spectroscopy}

NMR data were acquired at $37{ }^{\circ} \mathrm{C}$ using a Bruker Avance II $500-\mathrm{MHz}$ NMR spectrometer or a Bruker Avance II $400-\mathrm{MHz}$ NMR spectrometer, both equipped with an inverse dual channel $\left({ }^{1} \mathrm{H}, \quad \mathrm{X}\right) \quad z$-gradient probehead (broadband inverse). One-dimensional ${ }^{1} \mathrm{H}$ NMR data were measured with 16-64 transients into $32 \mathrm{k}$ data points over a width of $15 \mathrm{ppm}$ using a classic presaturation to eliminate the water resonance. A relaxation delay of $6 \mathrm{~s}$ was applied between transients. 
Two-dimensional ${ }^{1} \mathrm{H}-{ }^{1} \mathrm{H}$ NMR correlation spectroscopy data were acquired over a frequency width of $12 \mathrm{ppm}$ in both $F_{2}$ and $F_{1}$ into $2 \mathrm{k}$ complex data points in $F_{2}$ (acquisition time 213 or $170 \mathrm{~ms}$ ) using 128 or $256 t_{1}$ increments. A relaxation delay of $2 \mathrm{~s}$ between transients was used for all experiments. The data were recorded using four or eight transients, depending on the samples. The water resonance was suppressed by means of a presaturation routine.

Two-dimensional ${ }^{1} \mathrm{H}-{ }^{13} \mathrm{C}$ heteronuclear single quantum coherence NMR data were acquired over an $\mathrm{F}_{2}$ frequency width of $12 \mathrm{ppm}$ into $2 \mathrm{k}$ complex data points (acquisition time 213 or $170 \mathrm{~ms}$ ). Sixteen to 32 transients were accumulated for each of $196 t_{1}$ increments over an $\mathrm{F}_{1}$ frequency width of $180 \mathrm{ppm}$ centred at $90 \mathrm{ppm}$. Phase-sensitive data were acquired in a sensitivity-improved manner using an echo-antiecho acquisition mode.

Two-dimensional ${ }^{1} \mathrm{H}-{ }^{13} \mathrm{C}$ heteronuclear multiple bond correlation NMR data were acquired over an $\mathrm{F}_{2}$ frequency width of $12 \mathrm{ppm}$ into $2 \mathrm{k}$ complex data points (acquisition time 213 or $170 \mathrm{~ms}$ ). Sixty-four to 96 transients were accumulated for each of $196 t_{1}$ increments over an $F_{1}$ frequency width of $200 \mathrm{ppm}$ centred at $100 \mathrm{ppm}$. Phasesensitive data were acquired in a sensitivity-improved manner using an echo-antiecho acquisition mode.

Two-dimensional ${ }^{1} \mathrm{H}$ diffusion-ordered spectroscopy (DOSY) NMR data were acquired with a standard longitudinal encode-decode pulsed-field-gradient stimulated echo sequence containing bipolar gradients [30, 31]. For all experiments, the airflow was increased to $670 \mathrm{l} / \mathrm{min}$, and the NMR tube was spun. Experimental parameters were $\Delta=100 \mathrm{~ms}$ (diffusion delay), $\tau=1 \mathrm{~ms}$ (gradient recovery delay) and $T=5 \mathrm{~ms}$ (eddy current recovery delay). For each data set, $4 \mathrm{k}$ complex points were collected, and the gradient dimension was sampled by means of 32 experiments in which the gradient strength was linearly increased from 1.0 to $50.8 \mathrm{G} / \mathrm{cm}$. The gradient duration $\delta / 2$ was adjusted to observe a near-complete signal loss at $50.8 \mathrm{G} / \mathrm{cm}$. Typically, the $\delta / 2$ delay was chosen in the 1.6-2.0-ms range. A 2-s recycle delay was used between scans for the data shown. For each data set, the spectral axis was processed with an exponential function $(3-5-\mathrm{Hz}$ line broadening), and a Fourier transform was applied to obtain $8 \mathrm{k}$ real points. The DOSY reconstruction was realised with $8 \mathrm{k}$ complex points in the detection dimension and with 256 points in the diffusion dimension. The number of scans ranged from 16 to 64 and was adapted to each sample. All NMR data were processed using TopSpin (versions 2.1 or 3.0, Bruker, Switzerland).

Electrospray ionisation mass spectrometry

Mass-spectrometric analyses were performed with an LTQ Orbitrap XL mass spectrometer (Thermo Fisher Scientific,
Bremen, Germany) equipped with a nanoelectrospray ion source.

For the mass spectrometry studies on the binding to selected biological ligands, stock solutions of $[1]\left[\mathrm{CF}_{3} \mathrm{SO}_{3}\right]_{6}$, Arg, His, Cys, and Lys, (each $0.286 \mathrm{mM}$ ) were prepared in $\mathrm{H}_{2} \mathrm{O}$. Solutions of $[\mathbf{1}]\left[\mathrm{CF}_{3} \mathrm{SO}_{3}\right]_{6}$ were incubated with the selected amino acid in a $1: 10$ molar ratio for $48 \mathrm{~h}$ at $37^{\circ} \mathrm{C}$. The samples were analysed in the positive ion mode with a voltage of $+700 \mathrm{~V}$ applied to the glass emitter (New Objective, Woburn, MA, USA). The tube lens was at $+150 \mathrm{~V}$ and the transfer capillary was held at $200{ }^{\circ} \mathrm{C}$. Spectra were acquired in Fourier transform mass spectrometry mode over an $\mathrm{m} / \mathrm{z}$, range from 100 to 2,000 with a resolution of 100,000 at $\mathrm{m} / \mathrm{z}, 400$. Calibration of the instrument was performed with ProteoMass LTQ/FT-Hybrid electrospray ionisation (ESI) positive mode calibration mix (Supelco Analytical, Bellefonte, PA, USA). The Xcalibur software package (version 2.0.7, Thermo Fisher Scientific) was used for instrument control and data processing.

\section{Results and discussion}

Synthesis and characterisation of the metallaprism

The hexanuclear metallaprism $[\mathbf{1}]\left[\mathrm{CF}_{3} \mathrm{SO}_{3}\right]_{6}$ (Fig. 1) was prepared from the dinuclear complex $\left[(p \text {-cymene })_{2} \mathrm{Ru}_{2}\right.$ $(\mathrm{dhnq}) \mathrm{Cl}_{2}$ ] and tpt in the presence of silver trifluoromethanesulfonate according to the literature method [32]. The ${ }^{1} \mathrm{H}$ NMR spectrum of $[1]^{6+}$ in $\mathrm{D}_{2} \mathrm{O}$ (Fig. S1) is relatively simple and contains two doublets at $\delta 8.51$ and 7.87 assigned to the $\mathrm{H}_{\alpha}$ and $\mathrm{H}_{\beta}$ protons of tpt, one singlet at 7.56 assigned to the 12 protons of dhnq, two doublets at $\delta 5.81$ and 5.47 assigned to the $p$-cymene ring protons and one septet at $\delta$ 2.74 , one singlet at $\delta 1.81$ and one doublet at $\delta 1.20$ for the methyl and isopropyl groups of the $p$-cymene protons. The ${ }^{13} \mathrm{C}$ chemical shifts (obtained from ${ }^{1} \mathrm{H}-{ }^{13} \mathrm{C}$ heteronuclear single quantum coherence and heteronuclear multiple bond correlation NMR spectra) were found at $\delta 171.0(\mathrm{CO}), 152.8\left(\mathrm{CH}_{\alpha}\right)$, $143.1\left(C_{\text {tpt }}\right), 137.9\left(C_{\mathrm{q}}\right), 123.6\left(\mathrm{CH}_{\beta}\right), 103.8\left(C_{p \text {-cymene }}\right)$, 100.3 ( $\left.C_{p \text {-cymene }}\right), 85.3$ ( $\left(\mathrm{CH}_{p \text {-cymene }}\right), 82.1\left(\mathrm{CH}_{p \text {-cymene }}\right), 30.4$ $\left(\mathrm{CH}\left(\mathrm{CH}_{3}\right)_{2}\right), 21.3\left(\mathrm{CH}\left(\mathrm{CH}_{3}\right)_{2}\right)$ and $16.3\left(\left(\mathrm{CH}_{3}\right)_{p \text {-cymene }}\right)$.

Interestingly, the spectrum in $\mathrm{D}_{2} \mathrm{O}$ showed an additional set of resonances for tpt at $\delta 7.87$ and 6.52; the corresponding ${ }^{13} \mathrm{C}$ shifts are found at $\delta 149.9$ and $121.0 \mathrm{ppm}$, respectively. These resonances seem to belong to a product of hydrolysis of the tpt residue which is formed immediately after dissolving the metallaprism in $\mathrm{D}_{2} \mathrm{O}$. In other solvents such as dimethyl sulfoxide, these resonances do not appear (Fig. S2), indicating that the presence of an impurity or a side product can be excluded. In addition, the DOSY spectrum of $[\mathbf{1}]^{6+}$ in $\mathrm{D}_{2} \mathrm{O}$ (Fig. S3) clearly shows that all resonances have the same diffusion coefficient, thus 

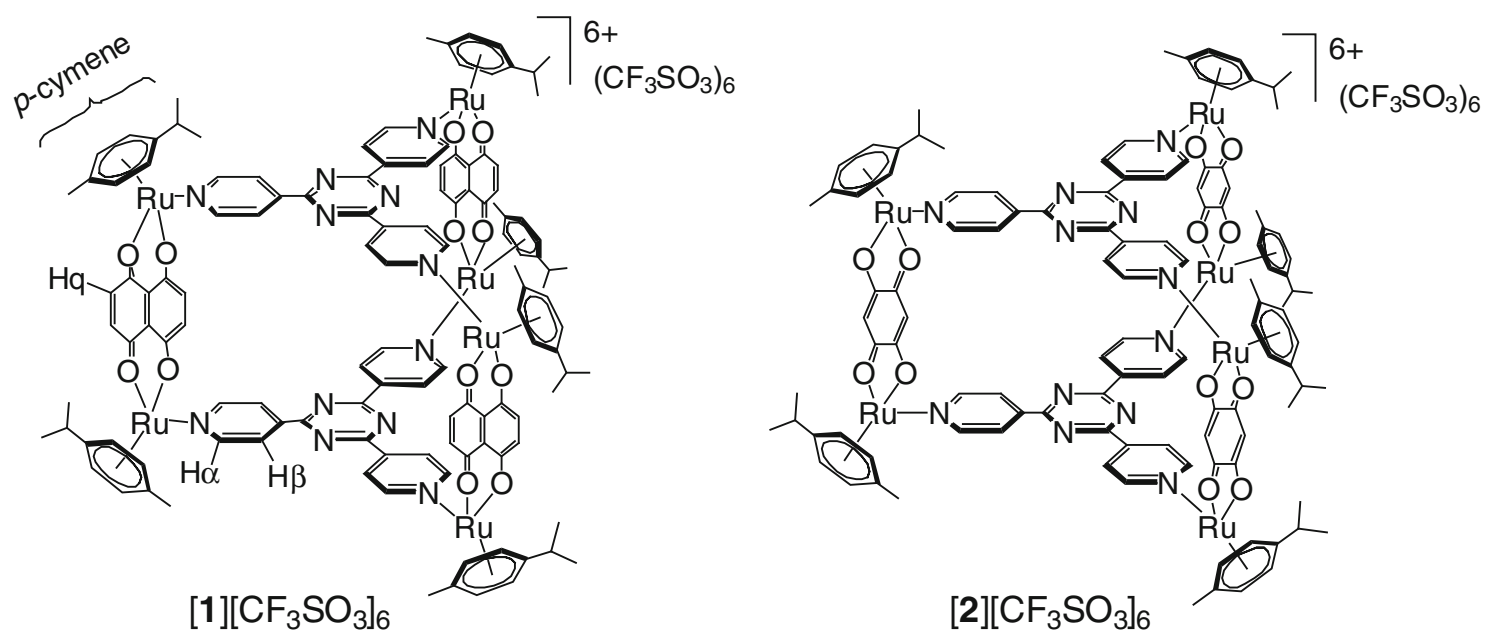

Fig. 1 Hexanuclear metallaprisms $[1]\left[\mathrm{CF}_{3} \mathrm{SO}_{3}\right]_{6}$ and $[2]\left[\mathrm{CF}_{3} \mathrm{SO}_{3}\right]_{6}$

suggesting that the metallaprism remains intact and does not disassemble in aqueous solution. In addition, the ESI mass spectrum of $[\mathbf{1}]\left[\mathrm{CF}_{3} \mathrm{SO}_{3}\right]_{6}$ exhibits only the expected fragments of the metallaprism with four remaining trifluoromethanesulfonate ions (Fig. S4). Therefore, it is not clear how $\mathrm{D}_{2} \mathrm{O}$ interacts with the tpt panels of the metallaprism $[\mathbf{1}]^{6+}$; however, hydrogen-bond interactions between the triazine core of tpt and $\mathrm{D}_{2} \mathrm{O}$ might provide an explanation.

\section{Stability in aqueous solution}

To evaluate and compare the stability of $[1]^{6+}$ in aqueous solution with the stability of metallaprism [2] ${ }^{6+}[21], 1 \mathrm{mg}$ $[1]\left[\mathrm{CF}_{3} \mathrm{SO}_{3}\right]_{6}$ was dissolved in $1.0 \mathrm{~mL} \mathrm{D}_{2} \mathrm{O}$, and the sample was analysed by ${ }^{1} \mathrm{H}$ NMR spectroscopy. To study the behaviour of $[\mathbf{1}]^{6+}$ in solutions containing chloride and other anions, we dissolved $[\mathbf{1}]\left[\mathrm{CF}_{3} \mathrm{SO}_{3}\right]_{6}$ in $50 \mathrm{mM} \mathrm{D} \mathrm{D}_{2} \mathrm{O}$ solutions of $\mathrm{NaCl}$ and $\mathrm{Na}_{2} \mathrm{CO}_{3}$. In all cases, ${ }^{1} \mathrm{H} \mathrm{NMR}$ spectra were recorded immediately after sample preparation, and every $2 \mathrm{~h}$ for $24 \mathrm{~h}$ (Fig. 2).

In the presence of chloride ions additional resonances appear immediately after dissolving $[\mathbf{1}]\left[\mathrm{CF}_{3} \mathrm{SO}_{3}\right]_{6}$. Typically, the tpt and dhnq resonances as well as the resonances of the two methyl groups of the $p$-cymene ligand are affected. These data are similar to the data found for metallaprism [2] ${ }^{6+}$ containing $\mathrm{dhbq}$ as a ligand [21], indicating that both prisms have similar behaviour in saline solution.

Different results were obtained when carbonate ions are present in solution. Directly after $[\mathbf{1}]\left[\mathrm{CF}_{3} \mathrm{SO}_{3}\right]_{6}$ is dissolved in a $\mathrm{D}_{2} \mathrm{O}$ solution containing $50 \mathrm{mM} \mathrm{Na} \mathrm{CO}_{3}$, the ${ }^{1} \mathrm{H} \mathrm{NMR}$ spectrum exhibits many additional resonances in the spectral region of tpt and dhnq (Fig. S5). A second set of resonances also appeared for the $p$-cymene resonances and the relative intensity of this second set of resonances changes over time. These experimental data suggest that the prism loses stepwise the tpt and the dhnq ligands, which are replaced by either $\mathrm{OH}^{-}$or $\mathrm{CO}_{3}^{-}$at the ruthenium atoms, as further indicated by the 2D ${ }^{1} \mathrm{H}$ DOSY spectrum (Fig. S6). These results corroborate the behaviour of metallaprism $[2]^{6+}$ upon the addition of carbonate ions [21]. Therefore, both metallaprisms $[\mathbf{1}]\left[\mathrm{CF}_{3} \mathrm{SO}_{3}\right]_{6}$ and $[2]\left[\mathrm{CF}_{3} \mathrm{SO}_{3}\right]_{6}$ are stable in aqueous solutions for about $2 \mathrm{~h}$ in solutions containing chloride ions, whereas they undergo a rapid dissociation in solutions containing carbonate ions. Additionally, the stability of hexacationic metallaprisms as a function of the $\mathrm{pH}$ was previously estimated for $[2]^{6+}$ [33]. The ${ }^{1} \mathrm{H}$ NMR spectra measured at $5 \mathrm{~min}, 1 \mathrm{~h}$ and $4 \mathrm{~h}$ in $\mathrm{D}_{2} \mathrm{O}$ with $50 \mathrm{mM}$ $\mathrm{NaCl}$ at $\mathrm{pH} 5.5$ showed that the metallaprisms remain stable for at least $4 \mathrm{~h}$ but slowly hydrolyse as described above.

Reactions with ascorbic acid and lactic acid

Most of the metallodrugs currently used in antitumour therapy, such as carboplatin and cisplatin, are administered intravenously and can therefore encounter various reactive biomolecules in the bloodstream. The concentrations of some biological molecules in the bloodstream [34] make them potential binding partners for metallodrugs. In particular, serum proteins such as albumin and transferrin can act in two different ways: the drugs bind to the proteins and are selectively released once they are inside the cancer cells, or these serum proteins may deactivate them even before they reach their targets [35-39]. As such, ascorbic acid, lactic acid, various amino acids and $\mathrm{GSH}$ were chosen and were subjected to analysis with $[1]\left[\mathrm{CF}_{3} \mathrm{SO}_{3}\right]_{6}$.

The spectra of the mixture of $[\mathbf{1}]^{6+}$ and lactic acid (ratio 1:10) over time were compared with the ${ }^{1} \mathrm{H}$ NMR spectra of free lactic acid and free $[1]^{6+}$. The NMR spectra 
Fig. 2 Stability of $[\mathbf{1}]^{6+}$ monitored by ${ }^{1} \mathrm{H}$ NMR spectroscopy for $24 \mathrm{~h}$. Left $[\mathbf{1}]^{6+}$ in $\mathrm{D}_{2} \mathrm{O}$, right $[\mathbf{1}]^{6+}$ in $\mathrm{D}_{2} \mathrm{O}$ with addition of $50 \mathrm{mM} \mathrm{NaCl}$

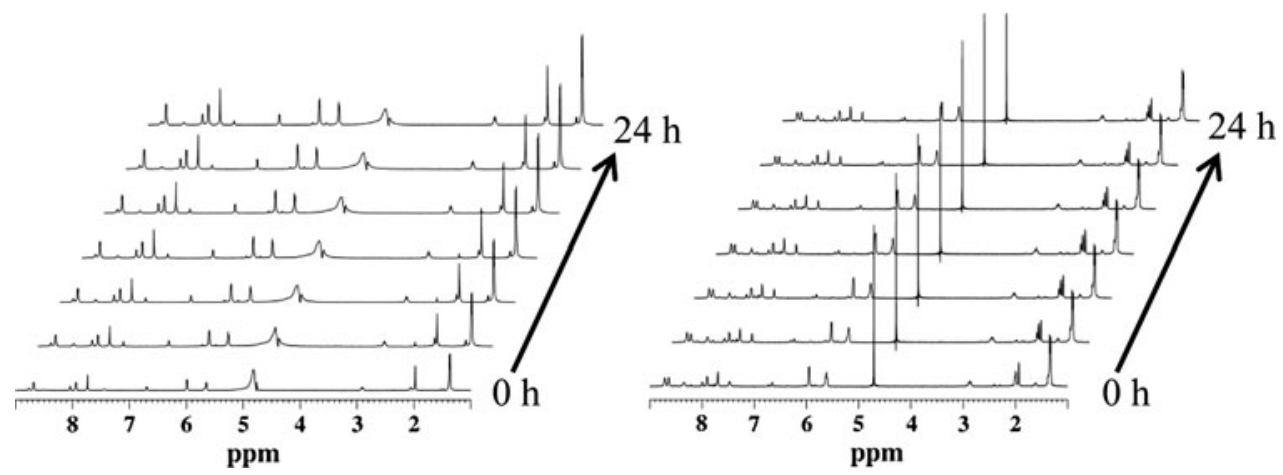

A

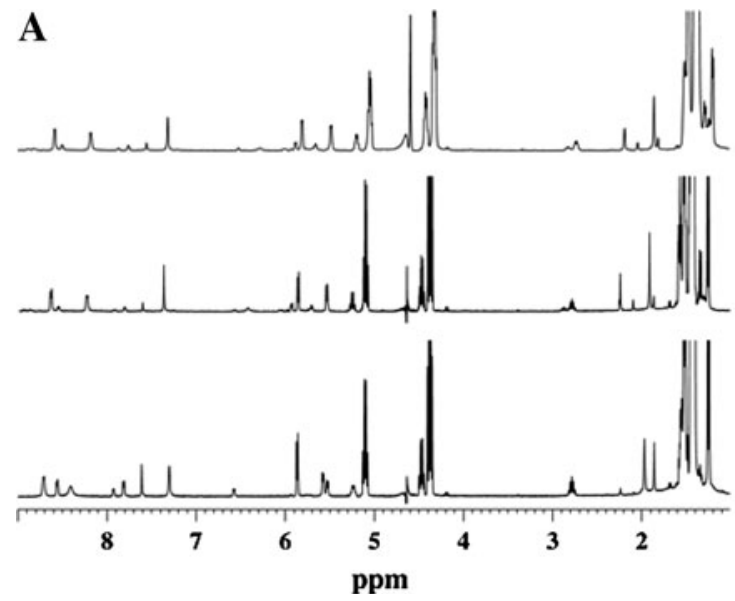

B

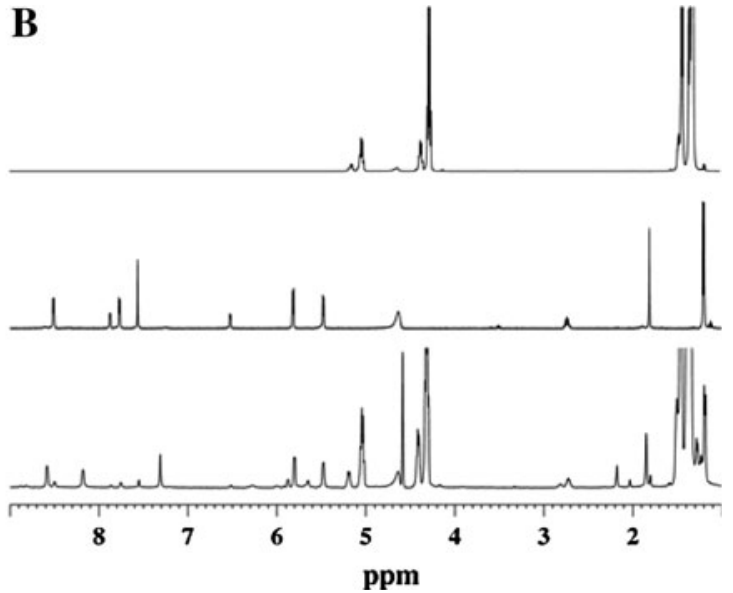

Fig. 3 a ${ }^{1} \mathrm{H}$ spectra of the mixture of $[\mathbf{1}]^{6+}$ and lactic acid at 0,12 and $24 \mathrm{~h}$ (bottom to top) and $\mathbf{b}$ a comparison of the spectrum of the mixture after $24 \mathrm{~h}$ with the spectra of free $[\mathbf{1}]^{6+}$ and free lactic acid (bottom to top)

exhibited some changes for the resonances of the prism (Fig. 3), probably due to hydrolysis. Analysis of the DOSY spectrum after $24 \mathrm{~h}$ reveals, however, that no adduct between lactic acid and the metallaprism has been formed (Fig. S7), since the DOSY spectrum exhibits two distinct set of resonances, one assignable to free lactic acid and the other to the free metallaprism. These results suggest that metallaprism $[1]^{6+}$ hydrolyses slightly faster in the presence of lactic acid but also that no strong interaction occurs between these two components.

The results obtained for the reaction between $[\mathbf{1}]^{6+}$ and ascorbic acid contrast with those obtained with lactic acid. Directly after the two components were mixed in a 1:6 ratio, the ${ }^{1} \mathrm{H}$ resonances of the metallaprism remained unchanged, but adjacent to the resonances of ascorbic acid $(\delta 3.75,4.05$ and 4.55$)$ new resonances at $\delta 4.75,4.25$, and 4.17 arose (Fig. 4). In agreement with the literature [40], these resonances are assigned to dehydroascorbic acid. The resonances of dehydroascorbic acid increase slightly in intensity over time, whereas the resonances of the protons associated with ascorbic acid decrease slightly in intensity. After about $72 \mathrm{~h}$ equilibrium is reached, and the conversion of ascorbic acid into dehydroascorbic did not proceed further (Chart S1). The total amount of ascorbic acid converted is about $4 \%$, which is slightly more than the amount of ascorbic acid converted into dehydroascorbic acid via autoxidation in $\mathrm{D}_{2} \mathrm{O}(1.3 \%$ after 2 weeks; Chart S2).

Analyses of the 2D ${ }^{1} \mathrm{H}$ DOSY spectrum recorded after $72 \mathrm{~h}$ revealed that a reaction had occurred and that the metallaprism had disassembled. Indeed, the ${ }^{1} \mathrm{H}$ DOSY NMR spectrum (Fig. 5) indicates that the two resonances of tpt at $\delta 9.11$ and 9.23 no longer belong to the rest of the prism. The DOSY spectrum also shows that no adduct is formed between the metal centre and ascorbic acid or dehydroascorbic acid, since the respective diffusion coefficients are distinct. It seems, therefore, that metallaprism $[1]^{6+}$ is able to slightly enhance the rate of oxidation of ascorbic acid to dehydroascorbic acid, and that it also simultaneously undergoes a partial disassembly with the loss of both tpt moieties. Interestingly, these experiments reveal that the oxidation of ascorbic acid is much slower and incomplete compared with that for metallaprism $[2]^{6+}$ and is also accompanied by the partial destruction of the metallaprism, which was not observed with $[2]^{6+}[21]$. In addition $[\mathbf{1}]^{6+}$ is dismembered in the presence of ascorbic 


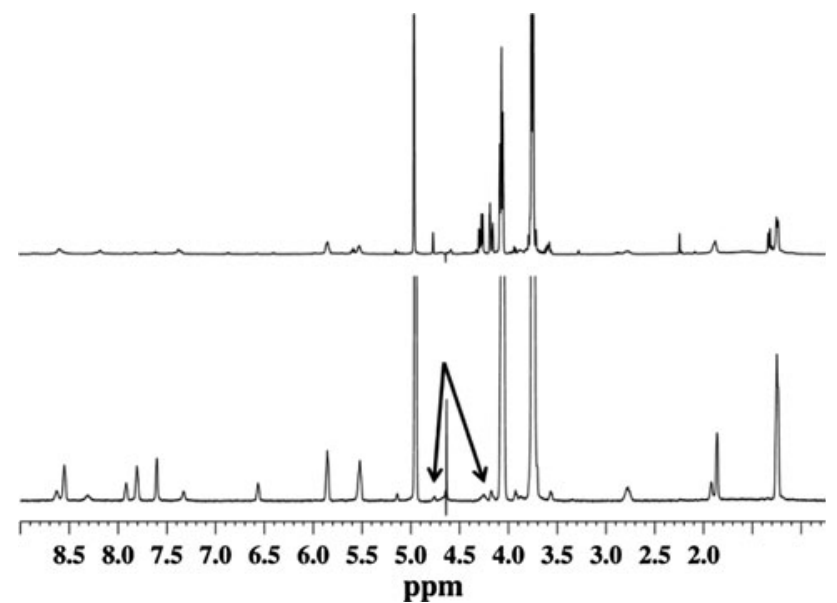

Fig. $4{ }^{1} \mathrm{H}$ spectrum of the mixture $[\mathbf{1}]^{6+}$ and ascorbic acid at $5 \mathrm{~min}$ (bottom). Adjacent to the resonances of ascorbic acid a new set of resonances appears indicated by black arrows. These resonances increase in intensity over time as can be seen in the spectrum measured after $72 \mathrm{~h}$ (top)

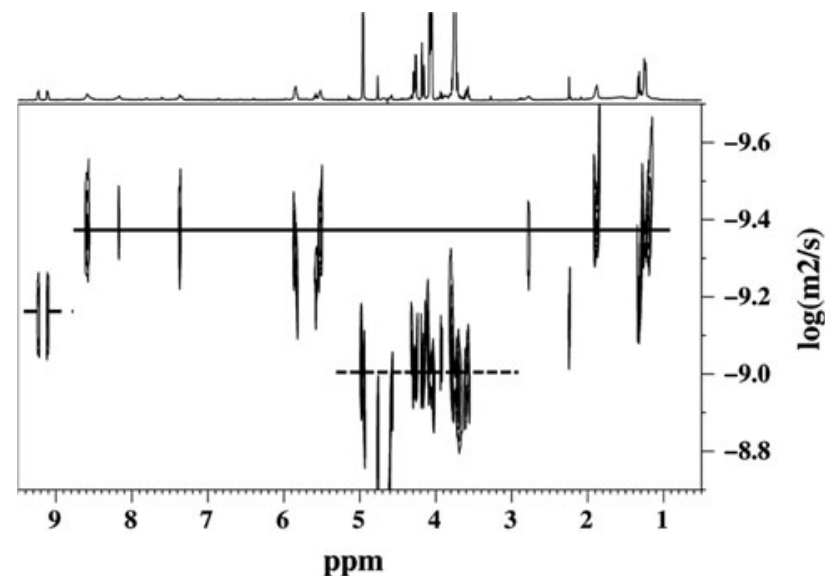

Fig. 5 Two-dimensional ${ }^{1} \mathrm{H}$ diffusion-ordered spectroscopy spectrum of the mixture of $[\mathbf{1}]^{6+}$ and ascorbic acid (ratio 1:6) after $72 \mathrm{~h}$. The partial disassembly of the prism is noticeable since the resonances of 2,4,6-tri(pyridine-4-yl)-1,3,5-triazine at $\delta 9.11$ and 9.23 have a diffusion coefficient different from that of the other resonances of the prism

acid, and it follows that $[\mathbf{1}]^{6+}$ can easily react with ascorbic acid or water as compared with metallaprism $[2]^{6+}$.

Reactions with Arg, Lys and His

Our recent investigations of metallaprism $[2]^{6+}[21]$ showed that it behaves rather differently from other ruthenium-based anticancer complexes [41]. In the same way, $[1]^{6+}$ showed no interactions with amino acids that are known to form stable complexes with ruthenium, such as Met [42]. Table S1 gives an overview of the reactions of $[\mathbf{1}]^{6+}$ with different biomolecules. In accordance with metallaprism $[2]^{6+}[21]$, the reactions between Arg, His and
Lys and $[1]^{6+}$ in $\mathrm{D}_{2} \mathrm{O}$ show significant changes in the NMR spectra within $24 \mathrm{~h}$, indicating that a reaction has occurred in each case. Notably, new resonances appear adjacent to the resonance of $\mathrm{H}_{\alpha}$ for all three amino acids (Fig. 6).

Analysis of the various NMR spectra revealed that the reactions of $[\mathbf{1}]^{6+}$ with $\mathrm{Arg}$, His and Lys are at first nearly identical to the reactions obtained with metallaprism $[2]^{6+}$ and suggest that chiral adducts are formed (Fig. 7). There are, however, significant differences: whereas the reactions were complete and occurred within minutes with metallaprism $[2]^{6+}$, the reactions of $[\mathbf{1}]^{6+}$ with Arg, His and Lys occurred much more slowly and reached a different equilibrium state. As shown in Fig. 6, the appearance of additional $\mathrm{H} \alpha$ resonances belonging to chelate adducts can be clearly observed only after $12 \mathrm{~h}$. For Arg and Lys, the reactions are complete after about $24 \mathrm{~h}$, as indicated by the NMR spectra (Fig. S9). On the other hand, for His, the NMR spectra obtained after $48 \mathrm{~h}$ once the steady state has been reached (i.e. when no changes in either the intensity or the chemical shifts of the resonances are observed) show that the ratio between free His and the newly formed His adduct is not 4:6 as expected if the reaction had been complete. The spectra show that only about $17 \%$ of His has reacted with $[\mathbf{1}]^{6+}$, which is confirmed by the presence of the resonances of the tpt and dhnq moieties in the NMR spectra, which are otherwise absent when the reaction is complete [21]. Taking into account the much longer reaction time and the incomplete reaction of His, $[1]^{6+}$ appears much less reactive than metallaprism $[2]^{6+}$ towards amino acids with basic side chain residues. The high cytotoxicity of $[\mathbf{1}]^{6+}$ may appear surprising at first, since this metallaprism is apparently more chemically inert than metallaprism $[2]^{6+}$. However, a recent study by Meier et al. [43] suggests an inverse correlation between metallodrugprotein interaction and cytotoxicity with regard to tumour cells. Similarly, we have shown in a recent study that trithiolato arene ruthenium complexes are highly cytotoxic despite their inertness towards biomolecules such as amino acids and nucleotides [44].

The formation of these adducts was confirmed by ESI measurements and 2D ${ }^{1} \mathrm{H}$ DOSY NMR spectra. The ESI mass spectra (Fig. S10-S12) for the mixture of $[1]^{6+}$ and the amino acids measured after an incubation time of $48 \mathrm{~h}$ show in each case a peak which can be assigned to the following adduct: $[(p \text {-cymene }) \mathrm{Ru}+\text { amino acid }+\mathrm{H}]^{+}$ (Table 1).

The 2D ${ }^{1} \mathrm{H}$ DOSY NMR spectra for mixtures of $[1]^{6+}$ and Arg or Lys are similar: they both exhibit resonances possessing a diffusion coefficient assignable to the ruthenium-amino acid adduct and others attributable to the free amino acid. According to the observations from the other NMR spectra, the DOSY spectrum of the mixture $[1]^{6+}$ and His displays three different diffusion coefficients, which 


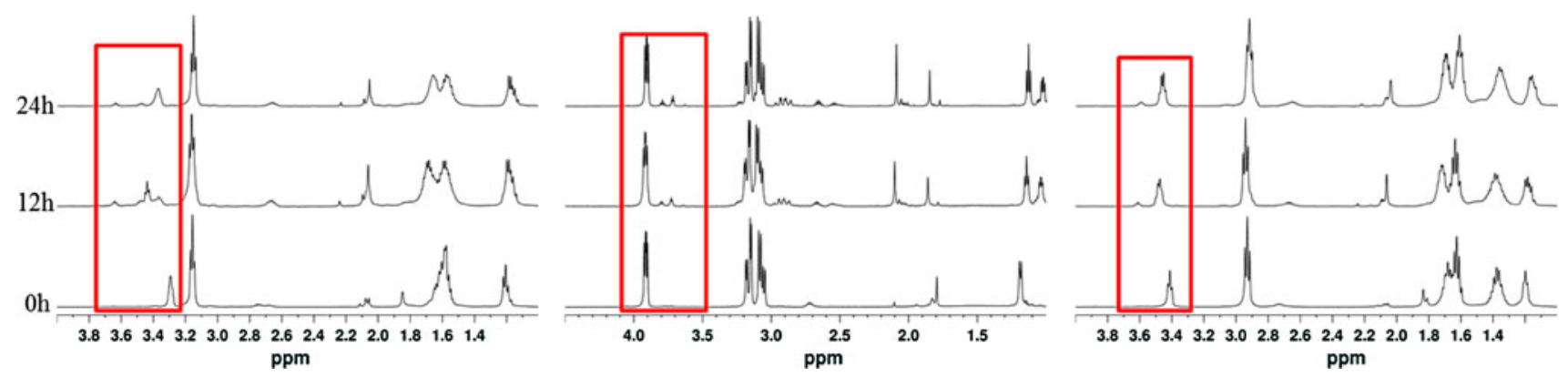

Fig. $6{ }^{1} \mathrm{H}$ NMR spectra of $[1]^{6+}$ and Arg, His and Lys (left to right) recorded over time. After $12 \mathrm{~h}$, the appearance of additional resonances near the original $\mathrm{H} \alpha$ resonance can be clearly observed

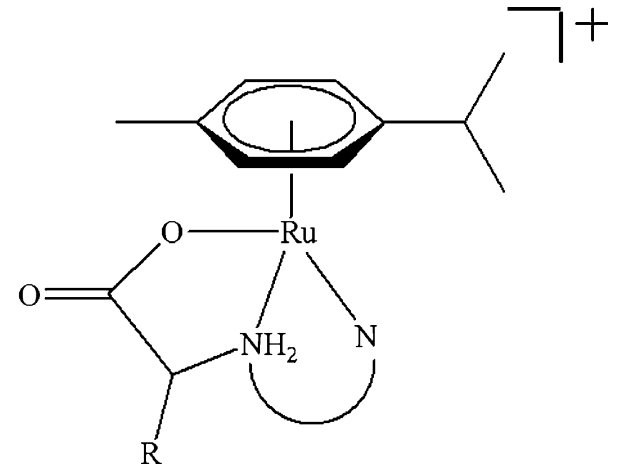

Fig. 7 General structural formula of the chelate adduct formed upon the addition of Arg, His and Lys

Table 1 Characteristic peaks observed in the electrospray ionisation mass spectra for mixtures of $[\mathbf{1}]^{6+}$ and Arg, $[\mathbf{1}]^{6+}$ and His, and $[\mathbf{1}]^{6+}$ and Lys

\begin{tabular}{lll}
\hline & $m / z$ & Proposed adduct \\
\hline$[\mathbf{1}]^{6+}+$ Arg & 409.12 & {$[(p \text {-cymene }) \mathrm{Ru}+\mathrm{Arg}+\mathrm{H}]^{+}$} \\
{$[\mathbf{1}]^{6+}+$ His } & 390.07 & {$[(p \text {-cymene }) \mathrm{Ru}+\mathrm{His}+\mathrm{H}]^{+}$} \\
{$[\mathbf{1}]^{6+}+$ Lys } & 381.11 & {$[(p \text {-cymene }) \mathrm{Ru}+\mathrm{Lys}+\mathrm{H}]^{+}$} \\
\hline
\end{tabular}

For the structure of $[\mathbf{1}]^{6+}$, see Fig. 1

belong, respectively, to the newly formed adduct, the free amino acid, and the intact metallaprism (Fig. S13-S15).

\section{Reactions with Cys and GSH}

The reactions between Cys and GSH with $[\mathbf{1}]^{6+}$ were also followed by 1D and 2D NMR spectroscopy as well as by ESI mass spectrometry. For Cys, no perceptible changes in the NMR spectra could be observed immediately after mixing the two components in $\mathrm{D}_{2} \mathrm{O}$. After about $12 \mathrm{~h}$, the ${ }^{1} \mathrm{H}$ NMR spectrum exhibits the set of resonances $(\delta 3.18$, 3.36 and 4.10) characteristic of cystine next to the resonances of Cys ( $\delta 2.99,3.07$ and 3.97) [45]. The resonances of cystine increase in intensity over time relative to the resonances of Cys, but even after 2 weeks the oxidation is still incomplete (Fig. S18). Compared with the autoxidation of Cys in $\mathrm{D}_{2} \mathrm{O}$ with or without trifluoromethanesulfonate ions present in the solution (Fig. S19), a higher amount of Cys is, however, converted into cystine in the presence of $[\mathbf{1}]^{6+}$, suggesting that metallaprism $[\mathbf{1}]^{6+}$ acts as a catalyst for this oxidation reaction.

Analyses of the DOSY spectrum suggests that once formed, cystine reacts with a fragment of the metallaprism (Fig. S17). Indeed, the various NMR spectra indicate that the tpt and dhnq moieties are removed from the ruthenium centre and that cystine coordinates to the remaining fragment of the prism. As observed with Arg, His and Lys, these findings suggest that cystine can act as a chelating ligand for the ruthenium atom and can replace the tpt and dhnq ligands in the initial prism. Interestingly, however, Cys does not bind to the prism, as revealed by the DOSY spectrum. These results are in stark contrast to the observation made by Wang et al. [22]. In the case of the $\left[\left(\eta^{6}\right.\right.$-biphenyl) $\left.\mathrm{RuCl}(\mathrm{en})\right]\left[\mathrm{PF}_{6}\right]$ complex (en is ethylenediamine), they observed the formation of an adduct between the ruthenium atom and both Cys and cystine. In our case the shifts of cystine bound to the ruthenium centre $(\delta 3.16,3.34$ and 4.09$)$ are very similar to those of free cystine $(\delta 3.22,3.41$ and 4.16) [45].

A plausible structure of the adduct formed upon the addition of cystine was established by analysing the ESI mass spectrum (Fig. 8). A characteristic peak is clearly visible at $\mathrm{m} / \mathrm{z}=710.04$, consistent with the formation of a complex containing two ruthenium atoms per cystine, [2(pcymene) $\mathrm{Ru}+$ cystine $+\mathrm{H}]^{+}$. The formation of such a diruthenium complex (Fig. 9) is rather surprising, since it markedly differs from the behaviour of the other amino acids with regard to $[\mathbf{1}]^{6+}$ and from the results we have obtained with metallaprism [2] ${ }^{6+}[21]$.

The reaction of GSH with metallaprism $[1]^{6+}$ in a $6: 1$ ratio reveals a rather unexpected result, since the resonances of Cys (GSH) at $\delta 2.89$ and 4.52 have completely disappeared from the ${ }^{1} \mathrm{H}$ NMR spectrum after only $24 \mathrm{~h}$, and only the resonances of cystine (GSSG, $\delta 2.95,3.23$ and 4.67) are visible, indicating that the oxidation of GSH to GSSG is completed after $24 \mathrm{~h}$ of incubation. Figure 10 


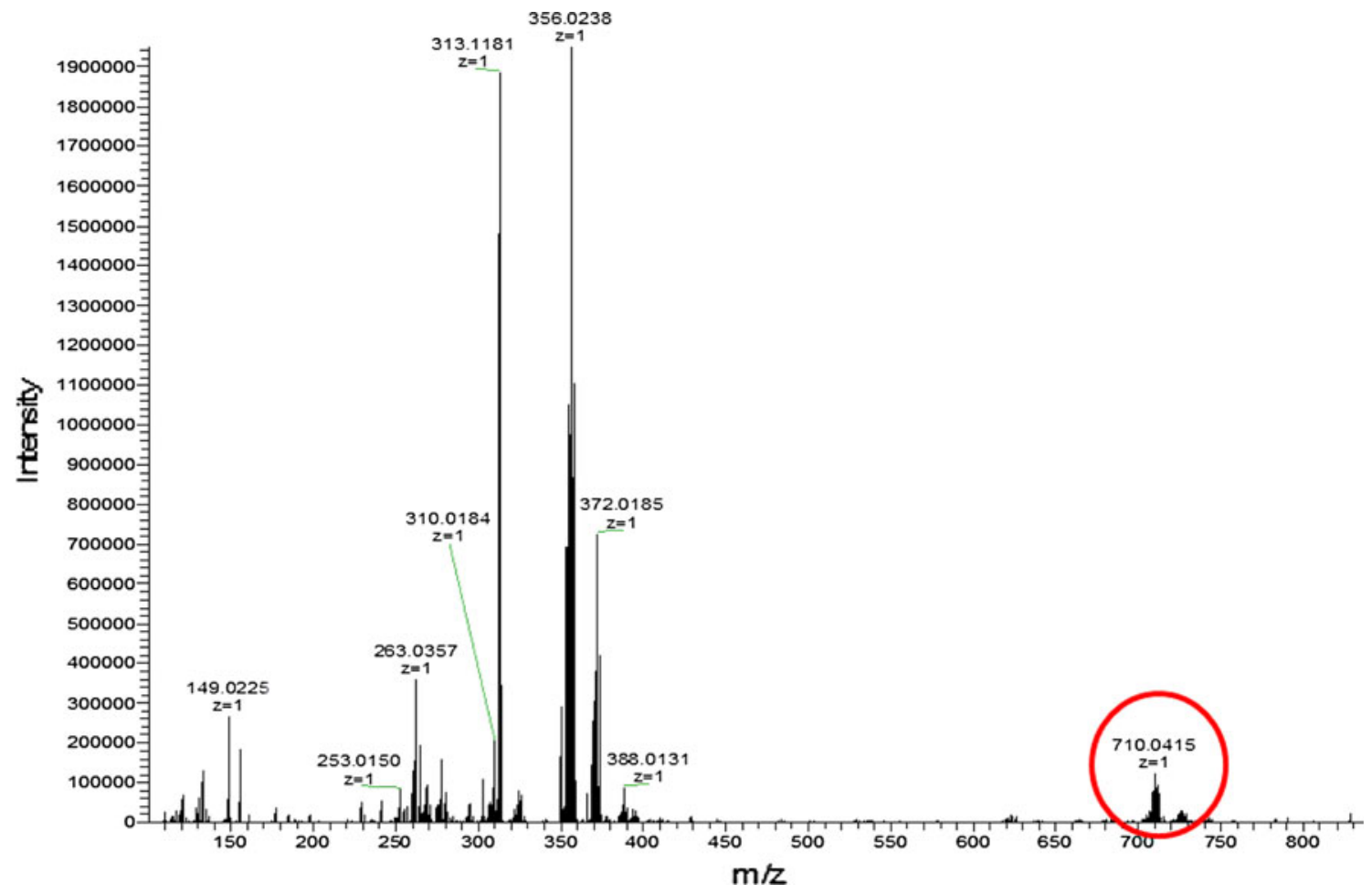

Fig. 8 Electrospray ionisation mass spectrum (positive mode) of $[1]\left[\mathrm{CF}_{3} \mathrm{SO}_{3}\right]_{6}$ and Cys (ratio 1:10) in $\mathrm{H}_{2} \mathrm{O}$ recorded after $48 \mathrm{~h}$

Fig. 9 Suggested [( $p$-cymene $) \mathrm{Ru}-$ cystine-Ru $(p$-cymene $)]^{+}$chelate complex obtained upon the addition of Cys to $[\mathbf{1}]^{6+}$
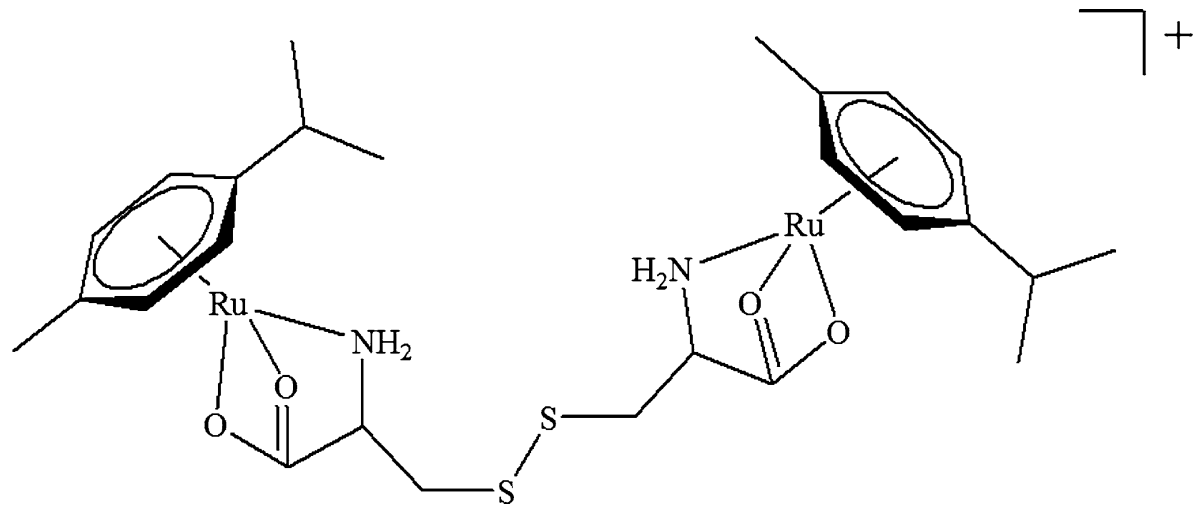

shows a comparison of the two $2 \mathrm{D}{ }^{1} \mathrm{H}-{ }^{1} \mathrm{H}$ correlation spectra obtained directly after incubation and after $24 \mathrm{~h}$. The black arrows indicate the resonances of Cys, which vanished completely after $24 \mathrm{~h}$, as clearly shown in the red spectrum. This result is surprising and strongly contrasts with the results obtained for the oxidation of Cys in the presence of $[\mathbf{1}]^{6+}$, which is not complete even after 14 days (Fig. S18).

The DOSY NMR spectrum of the mixture recorded after $24 \mathrm{~h}$ (Fig. S20) indicates that metallaprism $[1]^{6+}$ loses both the tpt and the dhnq ligand and coordinates to GSSG. Rather surprisingly, the oxidation of GSH to GSSG is completed faster in the presence of $[\mathbf{1}]^{6+}$ than in the presence of $[2]^{6+}$. Also, the formation of an adduct could not be observed with $[2]^{6+}$. This very different behaviour of $[1]^{6+}$ compared with $[2]^{6+}$ with regard to both Cys and GSH might explain the significant differences in cytotoxicity of the two metallaprisms (for $[1]^{6+}, \mathrm{IC}_{50}=2 \mu \mathrm{M}$ with regard to the A2780 cancer cell line, and for $[2]^{6+}$, $\left.\mathrm{IC}_{50}=23 \mu \mathrm{M}\right)$.

\section{Conclusions}

In this study we have shown that metallaprism $[\mathbf{1}]^{6+}$ reacts with various biological ligands and forms different adducts. As previously observed with metallaprism $[2]^{6+}$, addition of Arg, His and Lys displaces both the tpt and the dhnq ligands, and chelate N,N,O arene ruthenium adducts are formed. Solutions of $[\mathbf{1}]^{6+}$ are also able to catalyse the 


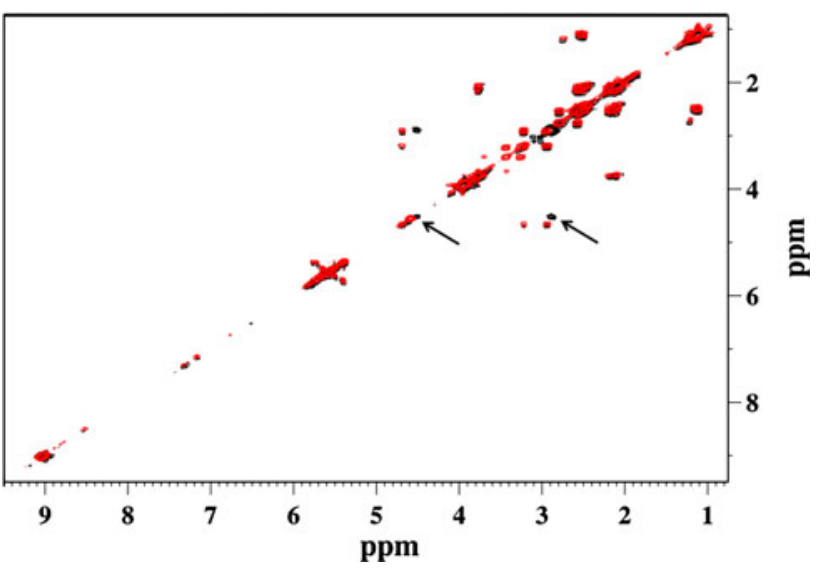

Fig. 10 Superimposition of the $2 \mathrm{D}{ }^{1} \mathrm{H}-{ }^{1} \mathrm{H}$ correlation spectroscopy NMR spectrum of $[\mathbf{1}]^{6+}$ recorded directly after addition of 6 equiv of glutathione (black) and after $24 \mathrm{~h}($ red $)$. The shifts of the $\mathrm{H}_{\alpha}$ and $\mathrm{H}_{\beta}$ resonances of Cys (black arrows) have vanished after $24 \mathrm{~h}$, indicating complete oxidation of glutathione to oxidised glutathione

oxidation of Cys to cystine and of GSH to GSSG. With both oxidised molecules, different adducts are formed, and these were not observed with previously investigated metallaprism $[2]^{6+}$. Furthermore, compared with metallaprism $[2]^{6+}$, the oxidation of Cys is incomplete and occurs much more slowly, whereas the oxidation of GSH is completed within $24 \mathrm{~h}$. The higher stability coupled with the oxidation ability of $[\mathbf{1}]^{6+}$ with regard to GSH might explain the significant differences in cytotoxicity of the two metallaprisms.

Interestingly, the kinetics of formation of the various adducts is much slower with metallaprism $[\mathbf{1}]^{6+}$ and moreover the reaction is incomplete with His. At a first glance, these differences could be attributed to the different lipophilic characters of the metallaprisms, since the replacement of dhbq by dhnq in $[\mathbf{1}]^{6+}$ simultaneously reduces the water solubility and increases the lipophilicity. However, recent studies have shown that encapsulation of a fluorescent pyrene molecule in these two metallaprisms allows the uptake of the guest within cancer cells to be monitored. Interestingly, the fluorescence observed after $24 \mathrm{~h}$ of incubation $(2 \mu \mathrm{M}$ concentration) of the host-guest systems for A2780 cancer cells was almost equivalent, suggesting similar internalisation and transport mechanisms despite the structural differences of the two metallaprisms $[33,46]$. Therefore, our results clearly demonstrate that the reactivity of ruthenium metallaprisms strongly depends on the building blocks used. It is therefore supposed that these ligands hamper the accessibility of the biological ligands to the reactive ruthenium atom, since dhnq is bulkier than dhbq (Fig. S21).

From our results, it is also obvious that the cytotoxicity of the metallaprisms is not correlated to the reactivity, since the results show that $[\mathbf{1}]^{6+}$ is more cytotoxic but less reactive than metallaprism $[2]^{6+}$. To further support this statement, we will investigate other ruthenium metallaprisms with bulkier ligands such hexamethylbenzene in place of $p$-cymene and compare the reactivity and especially the effects on the stability of the prism.

Acknowledgments J.F. thanks the Department of Chemistry and Biochemistry of the University of Bern for financial support. A generous loan of ruthenium chloride hydrate from the Johnson Matthey Technology Centre is gratefully acknowledged.

\section{References}

1. Rosenberg B, Van Camp L, Grimley EB, Thomson AJ (1967) J Biol Chem 242:1347-1352

2. Gasser G, Ott I, Metzler-Nolte N (2011) J Med Chem 54:3-25

3. Bergamo A, Sava G (2011) Dalton Trans 40:7817-7823

4. Bergamo A, Gaiddon C, Schellens JHM, Beijnen JH, Sava G (2012) J Inorg Biochem 106:90-99

5. Dwyer FP, Gyarfas EC, Rogers WP, Koch JH (1952) Nature 170:190-191

6. Clarke MJ (1980) Met Ions Biol Syst 11:231-283

7. Süss-Fink G (2010) Dalton Trans 39:1673-1688

8. Groessl M, Hartinger CG, Polec-Pawlak K, Jarosz M, Dyson PJ, Keppler BK (2008) Chem Biodivers 5:1609-1614

9. Rademaker-Lakhai JM, Van DBD, Pluim D, Beijnen JH, Schellens JHM (2004) Clin Cancer Res 10:3717-3727

10. Matsumura Y, Maeda H (1986) Cancer Res 46:6387-6392

11. Fujita M, Yazaki J, Ogura K (1990) J Am Chem Soc 112:56455646

12. Fujita M, Oguro D, Miyazawa M, Oka H, Yamaguchi K, Ogura K (1995) Nature 378:469-471

13. Kusukawa T, Fujita M (1998) Angew Chem Int Ed 37:3142-3144

14. Kusukawa T, Fujita M (2002) J Am Chem Soc 124:13576-13582

15. Ferrer M, Gutierrez A, Rodriguez L, Rossell O, Ruiz E, Engeser M, Lorenz Y, Schilling R, Gomez-Sal P, Martin A (2012) Organometallics 31:1533-1545

16. Vajpayee V, Yang YJ, Kang SC, Kim H, Kim IS, Wang M, Stang PJ, Chi K-W (2011) Chem Commun 47:5184-5186

17. Vajpayee V, Song YH, Yang YJ, Kang SC, Kim H, Kim IS, Wang M, Stang PJ, Chi K-W (2011) Organometallics 30:32423245

18. Therrien B, Süss-Fink G, Govindaswamy P, Renfrew AK, Dyson PJ (2008) Angew Chem Int Ed 47:3773-3776

19. Govindaswamy P, Furrer J, Süss-Fink G, Therrien B (2008) Z Anorg Allg Chem 634:1349-1352

20. Mattsson J, Govindaswamy P, Furrer J, Sei Y, Yamaguchi K, Süss-Fink G, Therrien B (2008) Organometallics 27:4346-4356

21. Paul LEH, Therrien B, Furrer J (2012) Inorg Chem 51:1057-1067

22. Wang F, Chen H, Parkinson JA, Murdoch PdS, Sadler PJ (2002) Inorg Chem 41:4509-4523

23. Hanif M, Henke H, Meier SM, Martic S, Labib M, Kandioller W, Jakupec MA, Arion VB, Kraatz H-B, Keppler BK, Hartinger CG (2010) Inorg Chem 49:7953-7963

24. Jungwirth U, Kowol CR, Keppler BK, Hartinger CG, Berger W, Heffeter P (2011) Antioxid Redox Signal 15:1085-1127

25. Dougan SJ, Habtemariam A, McHale SE, Parsons S, Sadler PJ (2008) Proc Natl Acad Sci USA 105:11628-11634

26. Giannini F, Süss-Fink G, Furrer J (2011) Inorg Chem 51:1055210554

27. Pitto-Barry A, Barry NPE, Zava O, Deschenaux R, Dyson PJ, Therrien B (2011) Chem Eur J 17:1966-1971 
28. Glasoe PK, Long FA (1960) J Phys Chem 64:188-190

29. Mikkelsen K, Nielsen SO (1960) J Phys Chem 64:632-637

30. Morris KF, Johnson CS (1992) J Am Chem Soc 114:3139-3141

31. Morris GA (2002) In: Grant DM, Harris RK (eds) Encyclopedia of nuclear magnetic resonance. Wiley, Chichester, pp 35-44

32. Barry NPE, Therrien B (2009) Eur J Inorg Chem 4695-4700

33. Zava O, Mattsson J, Therrien B, Dyson PJ (2010) Chem Eur J $16: 1428-1431$

34. Dyson PJ, Sava G (2006) Dalton Trans 1929-1933

35. Clarke MJ, Zhu F, Frasca DR (1999) Chem Rev 99:2511-2533

36. Allardyce CS, Dyson PJ (2001) Platin Metal Rev 45:62-69

37. Timerbaev AR, Hartinger CG, Aleksenko SS, Keppler BK (2006) Chem Rev 106:2224-2248

38. Jakupec MA, Galanski M, Arion VB, Hartinger CG, Keppler BK (2008) Dalton Trans 183-194
39. Hartinger CG, Keppler BK (2007) Electrophoresis 28:3436-3446

40. Nishikawa Y, Kurata T (2000) Biosci Biotechnol Biochem 64:476-483

41. Bergamo A, Masi A, Dyson PJ, Sava G (2008) Int J Oncol 33:1281-1289

42. Sheldrick WS, Exner R (1992) Inorg Chim Acta 195:1-9

43. Meier SM, Hanif M, Kandioller W, Keppler BK, Hartinger CG (2012) J Inorg Biochem 108:91-95

44. Giannini F, Furrer J, Ibao A-F, Süss-Fink G, Therrien B, Baquie M, Zava O, Dyson PJ, Štěpnička P (2012) J Biol Inorg Chem. doi: 10.1007/s00775-012-0911-2

45. Nakayama T, Isobe T, Nakamyiya K, Edmonds JS, Shibata Y, Morita M (2005) Magn Reson Chem 43:543-550

46. Barry NPE, Zava O, Dyson PJ, Therrien B (2011) Chem Eur J 17:9669-9677 